\title{
Saltation-layer structure of drifting snow observed in wind tunnel
}

\author{
Takeshi Sato, Kenji Kosugi, Atsushi Sato \\ Shinjo Branch of Snow and Ice Studies, National Research Institute for Earth Science and Disaster Prevention, Tokamachi, \\ Shinjo, Tamagata 996-0091, Japan
}

\begin{abstract}
The saltation-layer structure of drifting snow was investigated using the wind tunnel in a cold room. Experiments were conducted under various snow-temperature and wind-speed conditions over loose and hard snow covers. Snow was seeded at the upwind end of the wind tunnel. Mass-flux profiles of drifting snow were measured with a snowparticle counter. The theoretical expression for the mass flux of saltating sand (Kawamura, 1948) was fitted to the measured profiles, and two parameters in the theoretical expression, saltation height $h_{0}$ and mass flux at the surface $q_{0}$, were determined. The main results are as follows: (1) In the case of hard snow cover, snow particles are hardly ejected and drifting snow is maintained by the seeded snow. The value of $h_{0}$ linearly increases with wind speed and decreases with snow temperature, and $q_{0}$ decreases with wind speed and is in proportion to seeding rate. (2) In the case of loose snow cover, erosion occurs under high-wind conditions and the contribution of the ejected snow particles to drifting snow is remarkable. The $h_{0}$ linearly increases with wind speed, but its value is smaller than the value over hard snow cover. Due to erosion, $q_{0}$ increases with wind speed. Snowdrift transport rate and $q_{0}$ do not change with seeding rate under low-wind conditions, because the drifting snow is saturated. Under high-wind conditions, however, both snowdrift transport rate and $q_{0}$ slightly increase with seeding rate.
\end{abstract}

\section{INTRODUCTION}

Snowdrift and poor visibility due to drifting snow sometimes cause disasters in snowy regions. Drifting snow also forms snow cornice in mountainous areas, which can trigger snow avalanches. The motion of snow particles in the air is classified as creep, saltation and suspension. Creep is limited to the rolling motion of particles on the snow surface. Saltation is the bounding motion of particles within a thin layer over the snow surface. Both creep and saltation are related to the formation of snowdrift and snow cornice. The suspension above the saltation layer is governed by turbulent diffusion, and suspended particles reduce visibility.

The structure of drifting snow has been studied not only in the field but also in the laboratory. For example, Schmidt (1982) observed the suspension layer with a snow-particle counter (SPG) and revealed its structure focusing on sizedistribution changes with height. Takeuchi and others (1975) pointed out that the saltation-layer structure depends on the snow type such as compacted snow or granular snow. Sugiura and others (1998) carried out wind-tunnel experiments using disintegrated compacted snow, and showed the wind-speed dependence of saltation-layer structure, analyzing every particle size. Saltation length of snow particles has also been investigated by some researchers (e.g. Maeno and others, 1995). The structure of the saltation layer, especially its temperature and snow-type dependence, has not yet been systematically clarified.

Snowdrift transport rate is an important quantity for estimating the dimensions of snowdrifts and snow cornices. The contribution of saltating snow particles to the total transport rate is large. Many researchers have observed the relationship between snowdrift transport rate and wind speed, but the results show much variability. This may be ascribed to conditions other than wind speed, so it is necessary to determine the variability of the saltation-layer structure of drifting snow and its causes.

In this study, mass-flux profiles of drifting snow were measured in the wind tunnel under various conditions of wind speed, snow temperature and snow-cover hardness in order to clarify the dependence of the saltation-layer structure on these conditions.

\section{METHOD OF EXPERIMENT}

The wind tunnel is a return-flow, closed circuit type with a test section $14 \mathrm{~m}$ long, $1 \mathrm{~m}$ wide, and $1 \mathrm{~m}$ high (Fig. 1). It is installed in a cold room of the Cryospheric Environment Simulator (CES) at the Shinjo Branch of Snow and Ice Studies. The air temperature of the cold room can be controlled between $-30^{\circ}$ and $25^{\circ} \mathrm{C}$. The wind tunnel itself has another air conditioner for fine control. The floor of the test section has a gutter $80 \mathrm{~cm}$ wide and $2 \mathrm{~cm}$ deep. The CES has a snowfall machine, and the artificial snow produced can be used in the drifting-snow wind-tunnel experiment. In this study, however, artificial snow which was stored in the cold room and allowed to sinter was disintegrated and put into the gutter. The snow surface was made smooth. A snow seeder at the upwind end of the test section supplied snow particles into the airflow to enhance the development of drifting snow. The same snow was used for the snow seeder as that spread on the floor. The rate of snow seeding can be 


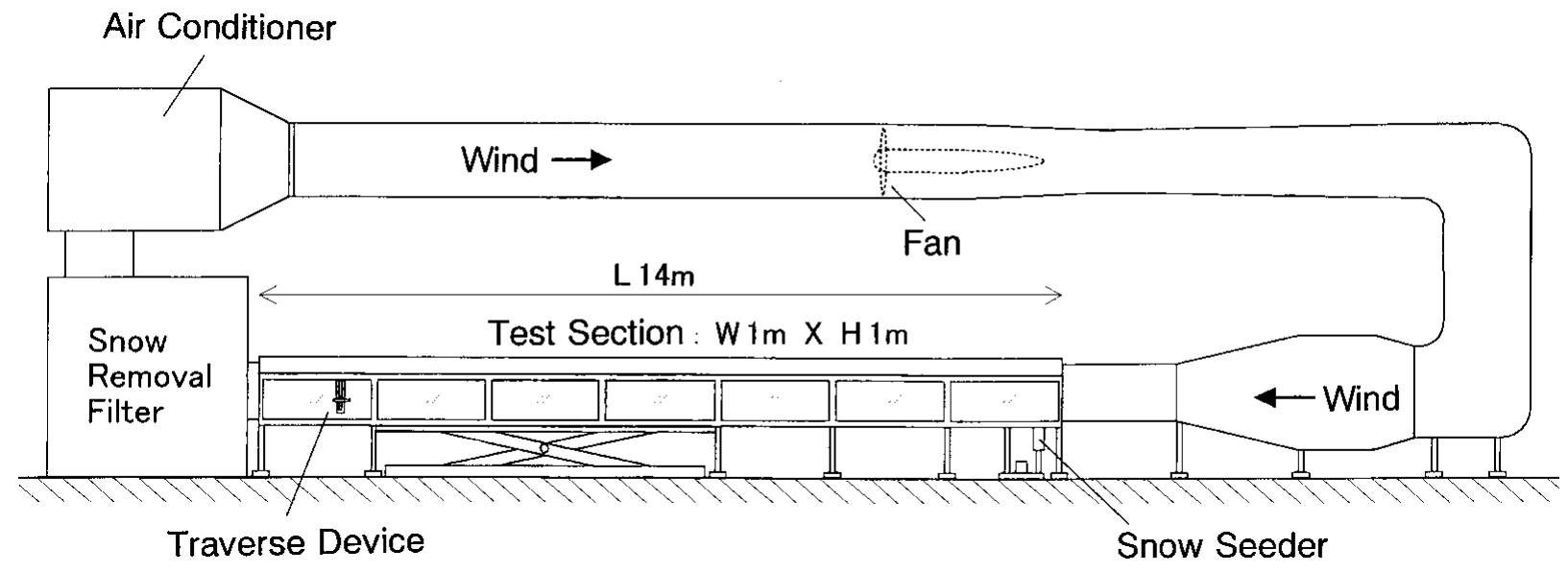

Fig. 1. Schematic of the wind tunnel.

varied from $1 \%$ to $100 \%$, where $100 \%$ corresponds to $3.55 \mathrm{~g} \mathrm{~cm}^{-1} \mathrm{~s}^{-1}$. The eolian snow particles are collected by a snow removal filter inserted after the downwind end of the test section. The first measurements were carried out after spreading the snow on the floor. In this case (hereafter, loose snow cover), sintering was not observed and the average hardness of snow cover was $23 \mathrm{kPa}$. In the second case (hereafter, hard snow cover), measurements were made after the snow spread on the floor had been allowed to sinter. The average hardness of hard snow cover was $66 \mathrm{kPa}$. For the two types of snow cover, snow temperature was adjusted to about $-2^{\circ},-6^{\circ}$ and $-15^{\circ} \mathrm{C}$ by controlling the air temperature in the wind tunnel.

The mass-flux profile was measured with a SPC, improved from the model described in Sato and others (1993). The SPC was fixed on the traverse device that can automatically scan within the test section under computer control. The SPG measurement was carried out at ten levels 2-30 cm above the snow surface. The sampling duration was 5 or $10 \mathrm{~s}$ at one level. The mass-flux values for both durations were compared under the same experimental conditions, and no difference was found. This assures that even the data of $5 \mathrm{~s}$ duration satisfy the stationary condition. The profiles were measured about $12 \mathrm{~m}$ downwind from the upwind end of the

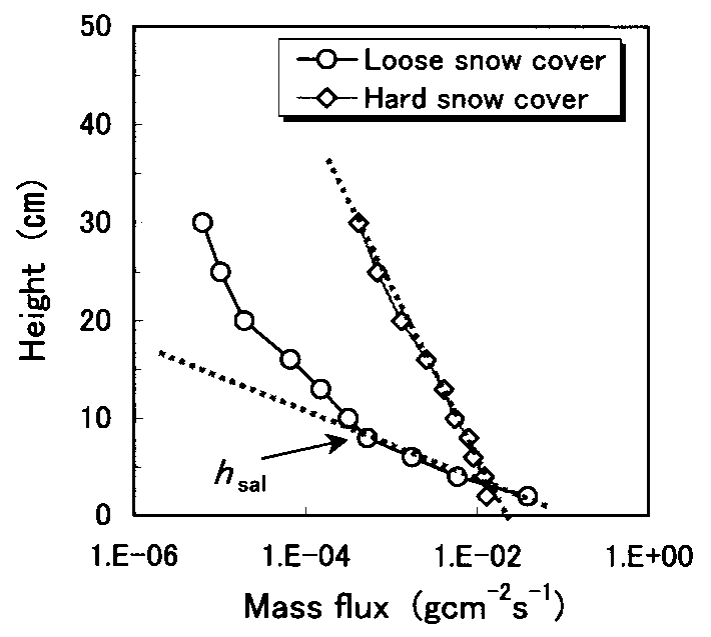

Fig. 2. Examples of measured mass-flux profile for hard and loose snow covers. Dotted lines denote Equation (1), and the definition of saltation-layer height $h_{\mathrm{sal}}$ is shown. test section. The dependence of the mass-flux profile on fetch distance could not be found over hard snow cover except for the first $1 \mathrm{~m}$ from the upwind end. The dependence was not checked in the case of loose snow cover. The mode of particle diameter, which depends on the height, was 100-300 $\mu \mathrm{m}$.

\section{ANALYSIS}

Kawamura (1948) derived the following theoretical expression for the mass flux of saltating sand particles with single size by assuming that particles are ejected vertically from the surface, and their ejection speed follows the Maxwell distribution:

$$
q(z)=q_{0} \exp \left[-z /\left(\pi h_{0}\right)\right]
$$

where $h_{0}$ and $q_{0}$ are the average of the attainable height of the saltating particles (hereafter, saltation height) and the mass flux at the surface, respectively. The mass flux at the surface is a function of the number and diameter of the ejected particles and the wind speed, which are originally treated as independent variables together with $h_{0}$.

In this study, Equation (1) was applied to the mass-flux profile of drifting snow, and the two parameters $h_{0}$ and $q_{0}$ were determined. Actually, the number and $h_{0}$ of saltating snow particles should depend on wind speed, and the diameter of particles ranges from several tens of to several hundred micrometers. Therefore, $h_{0}$ can be regarded as the mean of such particles, while $q_{0}$ will depend on the conditions of the surface as well. In the following, dependence of the two parameters on wind speed, snow temperature, seeding rate and snow type (hardness) will be shown.

Examples of the measured mass-flux profile are illustrated in Figure 2 together with the fitted expression. The upper limit of the applicability of Equation (1) cannot be defined a priori, but should be determined by some other means. In this study, the height where Equation (1) deviates from the measured profile is defined as the saltation-layer height $h_{\text {sal }}$. Although snowdrift transport rate can be calculated as $\pi h_{0} q_{0}$ by integrating Equation (1) from the surface to infinity, in this analysis it was obtained by integrating the measured mass flux from the surface to the top level $(30 \mathrm{~cm})$, where regressively obtained $q_{0}$ was substituted for the mass flux at the surface. This means that the snowdrift transport rate does not include the contribution of creep. 

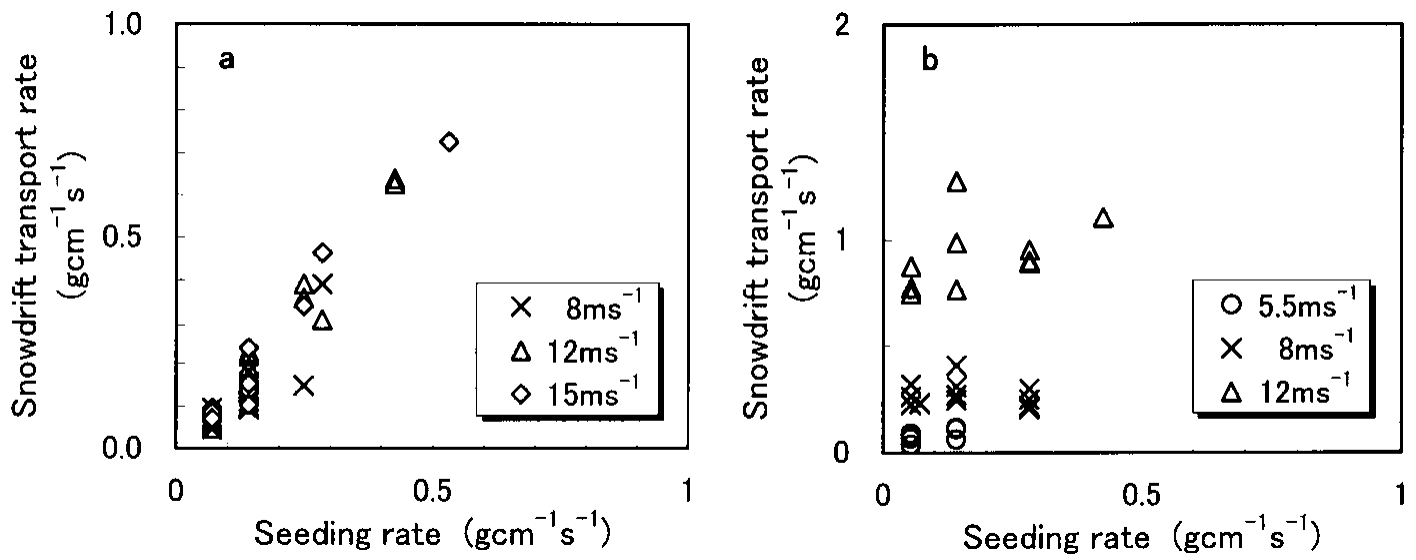

Fig. 3. Relationship between snowdrift transport rate and seeding rate for hard snow cover $(a)$ and for loose snow cover ( $b)$. Data are plotted regardless of snow temperature, and parameter is wind speed.

\section{RESULTS AND DISGUSSION}

\section{Snowdrift transport rate}

Temperature dependence of snowdrift transport rate was not remarkable for either hard or loose snow cover. Figure 3 shows the relationship between snowdrift transport rate and seeding rate. If the two rates coincide, the ejection of new-snow particles is negligible and the drifting snow in the wind tunnel is maintained by seeded snow. This approximately holds for hard snow cover as shown in Figure $3 \mathrm{a}$.

In the case of loose snow cover, however, snowdrift transport rate is almost constant for wind speeds of 5.5 and $8 \mathrm{~m} \mathrm{~s}^{-1}$ regardless of seeding rate, and it slightly increases with seeding rate for a wind speed of $12 \mathrm{~m} \mathrm{~s}^{-1}$. This implies that the drifting snow is saturated in the wind tunnel at low wind speed but not at high wind speed. This conclusion is supported by the observation after each measurement that the snow surface was partly eroded and some snow accumulation occurred. Snowdrift transport rate is almost the same as seeding rate for a wind speed of $5.5 \mathrm{~m} \mathrm{~s}^{-1}$, and is much larger than seeding rate for a wind speed of $12 \mathrm{~m} \mathrm{~s}^{-1}$, which can be explained by the enhanced erosion under higher-wind conditions.

\section{Saltation height, $h_{0}$}

Figure 4 shows the wind-speed dependence of saltation height $h_{0}$. In the case of hard snow cover (Fig. 4a), $h_{0}$ increases almost linearly with wind speed and it decreases monotonously as snow temperature rises. This snow-temperature dependence can be seen more clearly in Figure 5a. Kobayashi (1972) reported that the restitution coefficient of ice decreases with temperature. This nature of ice may account for the snow-temperature dependence of $h_{0}$ in the case of hard snow cover.

In the case of loose snow cover, similar wind-speed dependence can be found in Figure $4 \mathrm{~b}$. The values of $h_{0}$ are smaller than those for hard snow cover, because the kinetic energy of an impacting snow particle is partly used to fracture the snow surface and/or rearrange the snow particles that remain on the surface as well as to eject some particles. Snow-temperature dependence of $h_{0}$ is not systematic (Fig. 5b).

The saltation height principally depends on the splash process at the snow surface, which is probably independent of the number of impacting particles. This is supported by Figure 6 where $h_{0}$ is almost constant regardless of seeding rate.

\section{Mass flux at the surface, $q_{0}$}

Since ejection of snow particles hardly occurs on hard snow cover, the total amount of drifting snow is almost the same as the supply from the snow seeder. The saltation height increases with wind speed, and saltating snow particles are distributed in a thicker layer as a result. This reduces the mass flux at the surface to conserve the snowdrift transport rate if seeding rate is fixed. The mass flux at the surface $q_{0}$ is
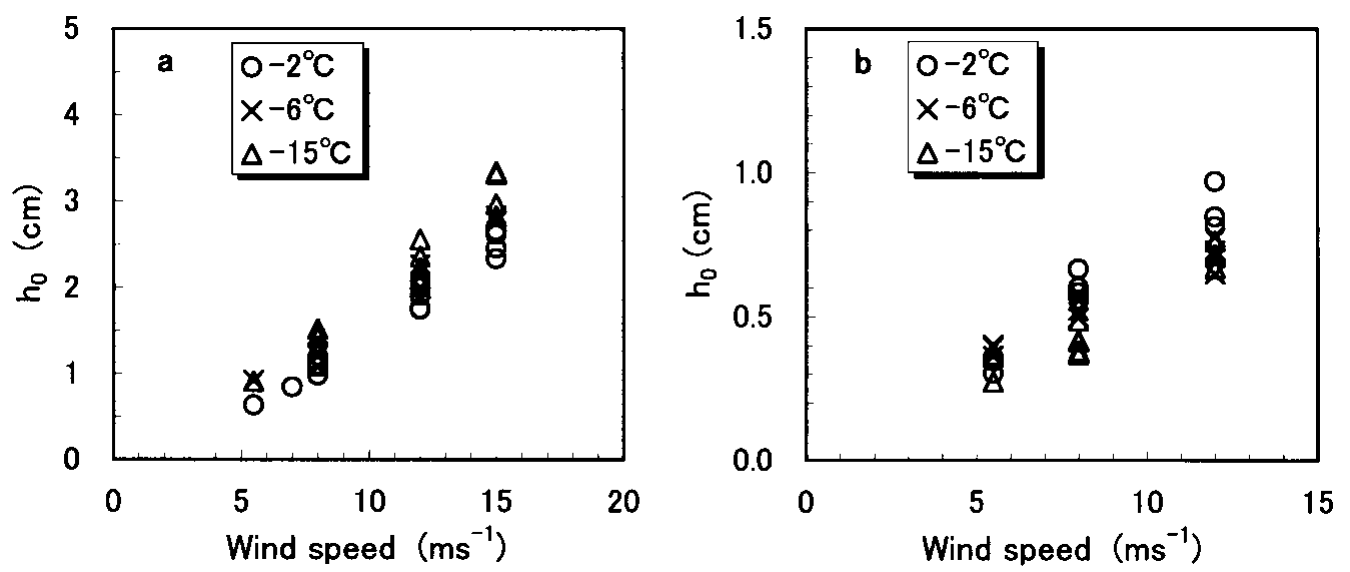

Fig. 4. Relationship between saltation height $h_{0}$ and wind speed for hard snow cover ( $\left.a\right)$ and for loose snow cover ( $b$ ). Data are plotted regardless of seeding rate, and parameter is snow temperature. 

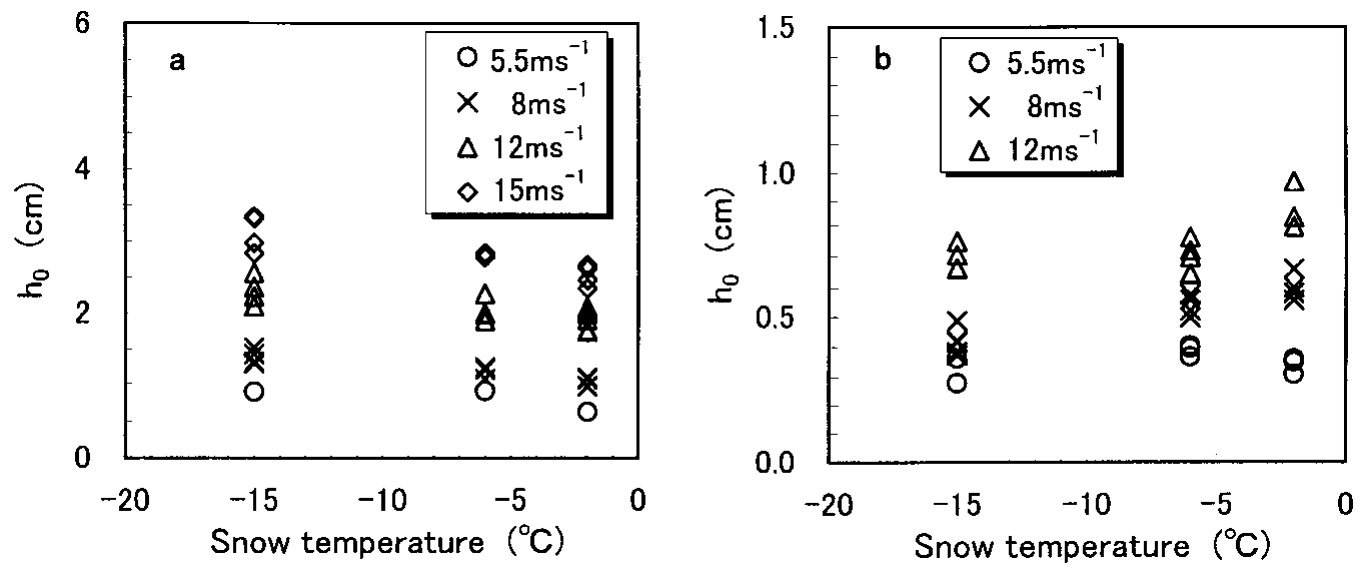

Fig. 5. Relationship between saltation height $h_{0}$ and snow temperature for hard snow cover $(a)$ and for loose snow cover ( $b$ ). Data are plotted regardless of seeding rate, and parameter is wind speed.
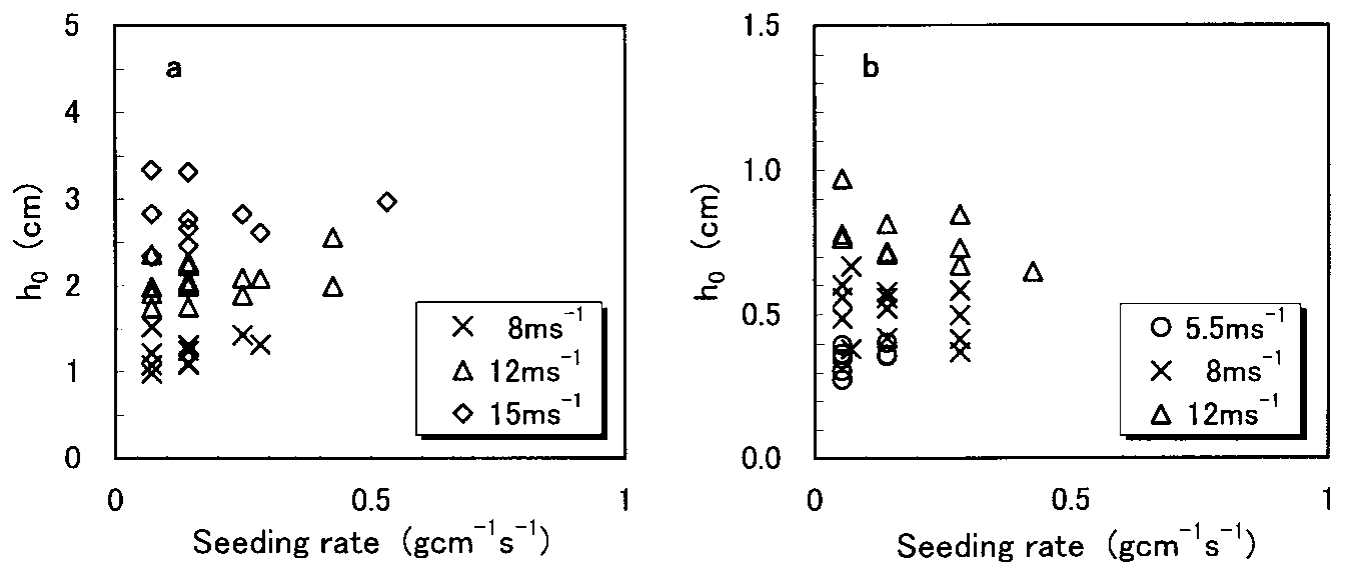

Fig. 6. Relationship between saltation height $h_{0}$ and seeding rate for hard snow cover $(a)$ and for loose snow cover $(b)$. Data are plotted regardless of snow temperature, and parameter is wind speed.
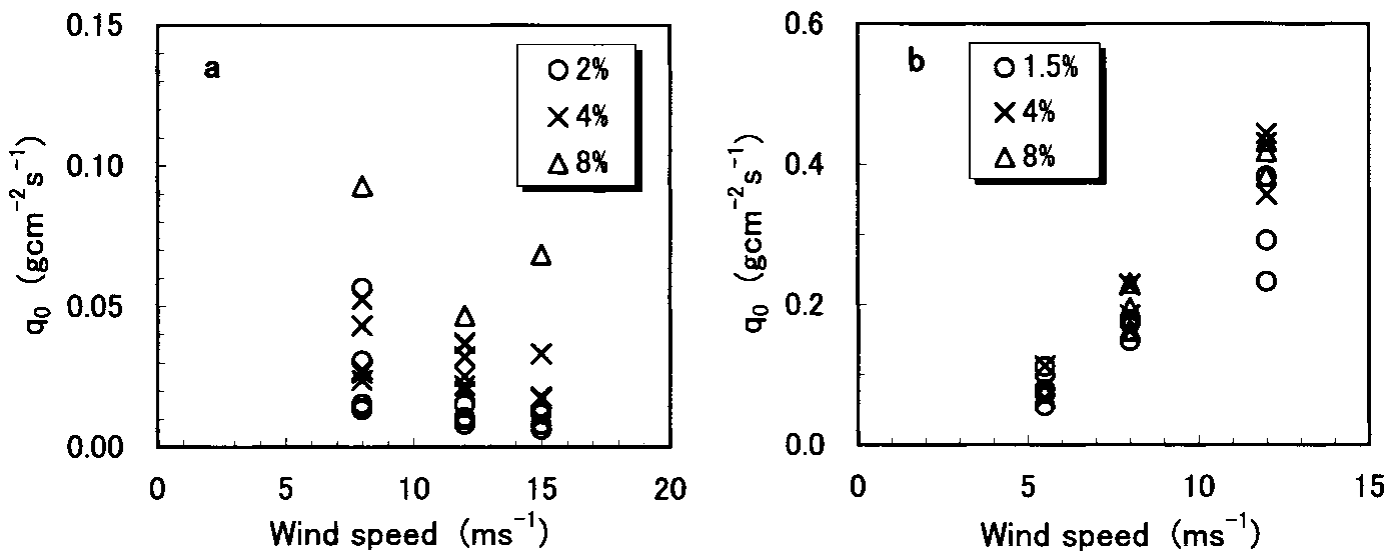

Fig. 7. Relationship between mass flux at the surface $q_{0}$ and wind speed for hard snow cover ( a) and for loose snow cover ( $b$ ). Data are plotted regardless of snow temperature. Parameter is the seeding rate expressed by percentage (100\% corresponds to $3.55 \mathrm{~g} \mathrm{~cm}^{-1} \mathrm{~s}^{-1}$ ).

plotted against wind speed regardless of snow temperature in Figure 7a, where $q_{0}$ decreases with wind speed.

Conversely, in the case of loose snow cover, $q_{0}$ increases with wind speed (Fig. 7b). Since impacting snow particles have larger kinetic energy under higher-wind conditions, they will eject more surface snow particles. As a result, the value of $q_{0}$ increases with wind speed.

The mass flux at the surface $q_{0}$ is proportional to seeding rate in the case of hard snow cover (Fig. 8a). The proportional constant does not vary much with snow temperature.
In the case of loose snow cover, a relationship with seeding rate similar to that with the snowdrift transport rate can be found in Figure $8 \mathrm{~b}$, that is, $q_{0}$ does not depend on seeding rate for wind speeds of 5.5 and $8 \mathrm{~m} \mathrm{~s}^{-1}$, and slightly increases with seeding rate for a wind speed of $12 \mathrm{~m} \mathrm{~s}^{-1}$. This tendency is attributed to the same cause mentioned before.

\section{Saltation-layer height, $h_{\mathrm{sal}}$}

Equation (1) holds in the whole height range of the measure- 

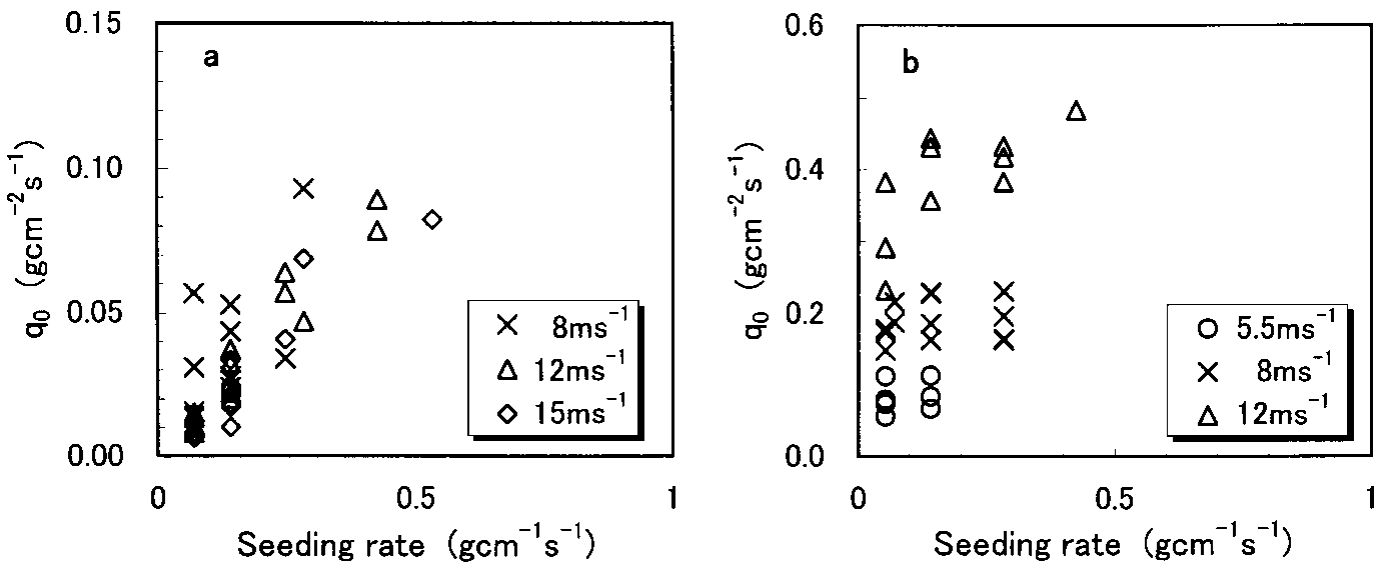

Fig. 8. Relationship between mass flux at the surface $q_{0}$ and seeding rate for hard snow cover ( $\left.a\right)$ and for loose snow cover (b). Data are plotted regardless of snow temperature, and parameter is wind speed.

ment in the case of hard snow cover, but the measured massflux profile deviates from Equation (1) at a certain height in the case of loose snow cover. The saltation-layer height $h_{\text {sal }}$ can be obtained from this height of deviation. In other words, only the saltation layer is observed over hard snow cover, and the suspension layer is also observed above the saltation layer over loose snow surface. These examples are shown in Figure 2. Figure 9 shows the relationship between $h_{\text {sal }}$ and $h_{0}$ for loose snow cover. Disregarding the snowtemperature dependence, the ratio $h_{\text {sal }} / h_{0}$ decreases with wind speed. The ratio is about 23 for a wind speed of $5.5 \mathrm{~m} \mathrm{~s}^{-1}$ and 14 for a wind speed of $12 \mathrm{~m} \mathrm{~s}^{-1}$. These values are much greater than the ratios of 5-8 observed in the field. This difference may be explained as follows: The turbulent intensity above the saltation layer is smaller in the wind tunnel than in the field, which weakens the entrainment of ejected and rebounding snow particles into the turbulence in the wind tunnel. This will prevent the downward evolution of the suspension layer, and the saltation layer will be thicker in the wind tunnel than in the field.

\section{CONGLUDING REMARKS}

Considering the dependence of snowdrift transport rate on seeding rate shown in Figure 3b, the drifting snow over

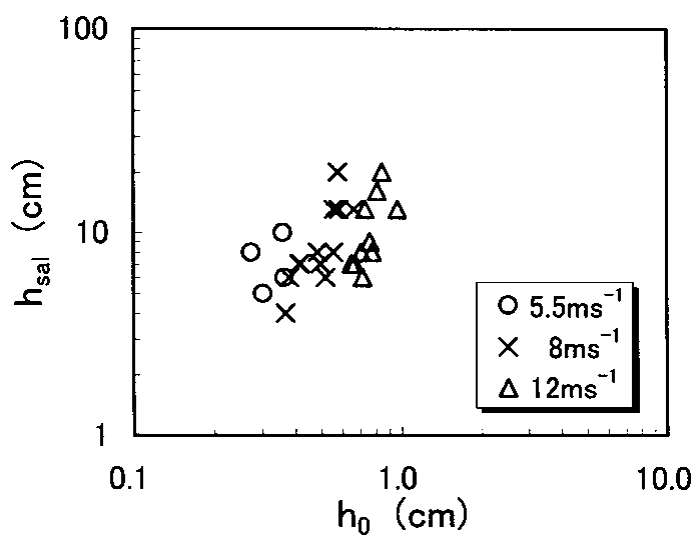

Fig. 9. Relationship between saltation-layer height $h_{\mathrm{sal}}$ and saltation height $h_{0}$ over loose snow cover. Data are plotted regardless of snow temperature and seeding rate. Parameter is wind speed. loose snow cover is saturated for wind speeds of 5.5 and $8 \mathrm{~m} \mathrm{~s}^{-1}$, and a quasi-saturated state can be expected for a wind speed of $12 \mathrm{~m} \mathrm{~s}^{-1}$. As a result, in the case of loose snow cover, the variability of the saltation-layer structure represented by the two parameters, $h_{0}$ and $q_{0}$, and their dependence on wind speed, snow temperature and snow type (hardness) can roughly be the feature of the saturated saltation layer of drifting snow. The drifting snow was produced over hard snow cover mainly from the snow supplied by the snow seeder, which corresponds to the situation in the field in which snow particles are advected from some upwind location to an area of hard snow cover.

The development of the saltation layer depends on the splash process at the snow surface. The splash process is influenced by the characteristics of snow cover such as the strengths of bonding and cohesion between adjacent snow particles, coefficients of friction and restitution of ice, as well as the size, speed and incident angle of impacting particles. The effectiveness of these parameters depends on the meteorological conditions and the state of snow.

The two types of snow cover examined in this study seem to be extreme opposites. Results are summarized as follows: (1) Snow particles are hardly ejected from hard snow cover due to their strong bonding. Snowdrift transport rate almost coincides with seeding rate. The saltation height increases with wind speed and is negatively correlated with snow temperature. The mass flux at the surface is in proportion to seeding rate and negatively correlates to wind speed. (2) Snow particles are not connected to each other in the case of loose snow cover, and erosion occurs under highwind conditions, which increases the snowdrift transport rate to higher values than the seeding rate. Saltation height is proportional to wind speed but is smaller than that over hard snow cover. The mass flux at the surface also increases with wind speed. The drifting snow is saturated for wind speeds of 5.5 and $8 \mathrm{~m} \mathrm{~s}^{-1}$, and snowdrift transport rate and the mass flux at the surface do not depend on seeding rate. At a wind speed of $12 \mathrm{~m} \mathrm{~s}^{-1}$, however, both snowdrift transport rate and mass flux at the surface slightly increase with seeding rate. The top of the saltation layer can be distinguished over loose snow cover, and the ratio of the saltation-layer height to the saltation height is greater than ratios observed in the field.

The hardness of snow will be a practical index to characterize the state of snow, and the intermediate-hardness 
case will be a subject of future research. The hardness of snow depends on the metamorphism of snow which is controlled by temperature and snow type. Prediction of the magnitude of drifting snow will be possible in the future if a snow-metamorphism model is combined with the presented and additional results. Such results will serve to provide a reasonable boundary condition for the numerical model of the suspension layer.

\section{ACKNOWLEDGEMENTS}

The authors wish to thank T. Takeda for operating the wind tunnel and equipment and for his help with the measurements.

\section{REFERENCES}

Kawamura, R. 1948. [Sand movement by wind.] Kagaku [Science], 18(11), 500-506. [In Japanese.]

Kobayashi, D. 1972. Studies of snow transport in low-level drifting snow. Contrib. Inst. Low Temp. Sci., Ser. A 24, 1-58.

Maeno, N., K. Nishimura, K. Sugiura and K. Kosugi. 1995. Grain size dependence of eolian saltation lengths during snow drifting. Geophys. Res. Lett., 22(15), 2009-2012.

Sato, T., T. Kimura, T. Ishimaru and T. Maruyama. 1993. Field test of a new snow-particle counter (SPG) system. Ann. Glaciol., 18, 149-154.

Schmidt, R. A. 1982. Vertical profiles of wind speed, snow concentration and humidity in blowing snow. Boundary-Layer Meteorol., 23(2), 223-246.

Sugiura, K., K. Nishimura, N. Maeno and T. Kimura. 1998. Measurements of snow mass flux and transport rate at different particle diameters in drifting snow. Cold Reg. Sci. Technol., 27(2), 83-89.

Takeuchi, M., K. Ishimoto and T. Nohara. 1975. [Study of drift snow transport.] Seppyo, 7. Jpn. Soc. Snow Ice, 37(3), 114-121. [In Japanese with English summary.] 